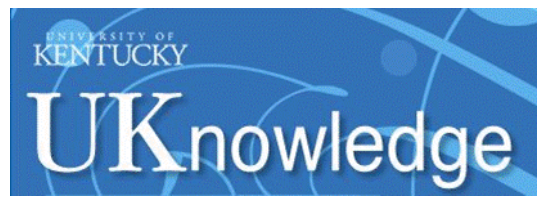

University of Kentucky

UKnowledge

Writing, Rhetoric, and Digital Studies Faculty Publications

Writing, Rhetoric, and Digital Studies

$6-2019$

\title{
Surveilling Strangers: The Disciplinary Biopower of Digital Genre Assemblages
}

\author{
Lauren E. Cagle \\ University of Kentucky, lauren.cagle@uky.edu
}

Follow this and additional works at: https://uknowledge.uky.edu/wrd_facpub

Part of the Communication Technology and New Media Commons, and the Rhetoric and Composition Commons

Right click to open a feedback form in a new tab to let us know how this document benefits you.

\section{Repository Citation}

Cagle, Lauren E., "Surveilling Strangers: The Disciplinary Biopower of Digital Genre Assemblages" (2019). Writing, Rhetoric, and Digital Studies Faculty Publications. 6.

https://uknowledge.uky.edu/wrd_facpub/6

This Article is brought to you for free and open access by the Writing, Rhetoric, and Digital Studies at UKnowledge. It has been accepted for inclusion in Writing, Rhetoric, and Digital Studies Faculty Publications by an authorized administrator of UKnowledge. For more information, please contact UKnowledge@lsv.uky.edu. 


\section{Surveilling Strangers: The Disciplinary Biopower of Digital Genre Assemblages \\ Digital Object Identifier (DOI) \\ https://doi.org/10.1016/j.compcom.2019.01.006}

Notes/Citation Information

Published in Computers and Composition, v. 52, p. 67-78.

(c) 2019 Elsevier Inc.

The copyright holder has granted the permission for posting this article here.

This manuscript version is made available under the CC-BY-NC-ND 4.0 license http://creativecommons.org/licenses/by-nc-nd/4.0/

The document available for download is the author's post-peer-review final draft of the article. 


\section{Surveilling Strangers: The Disciplinary Biopower of Digital Genre Assemblages}

Content warning: In sections 1 and 4, this article quotes examples of transmisic and anti-Islamic language. They have been placed in footnotes, so readers can more easily elect whether to read them.

\section{Introduction}

On September 21, 2012, a user with the handle "european_douchebag" uploaded a photograph to the online forum Reddit with the caption "I'm not sure what to conclude from this." The user posted it on a subreddit, or messageboard dedicated to a specific category of posts, titled "r/funny." As the name suggests, the messageboard is used to share "funny" content, including photos, memes, drawings, videos and other media. The uploaded photo is a snapshot of a woman standing in a line, looking down at her phone. She and others around her are carrying backpacks. The woman is dressed casually in yoga pants and a t-shirt. She is wearing stylish glasses and a tall black turban, and she has visible facial hair. Nothing indicates that she knows a picture is being taken of her. 


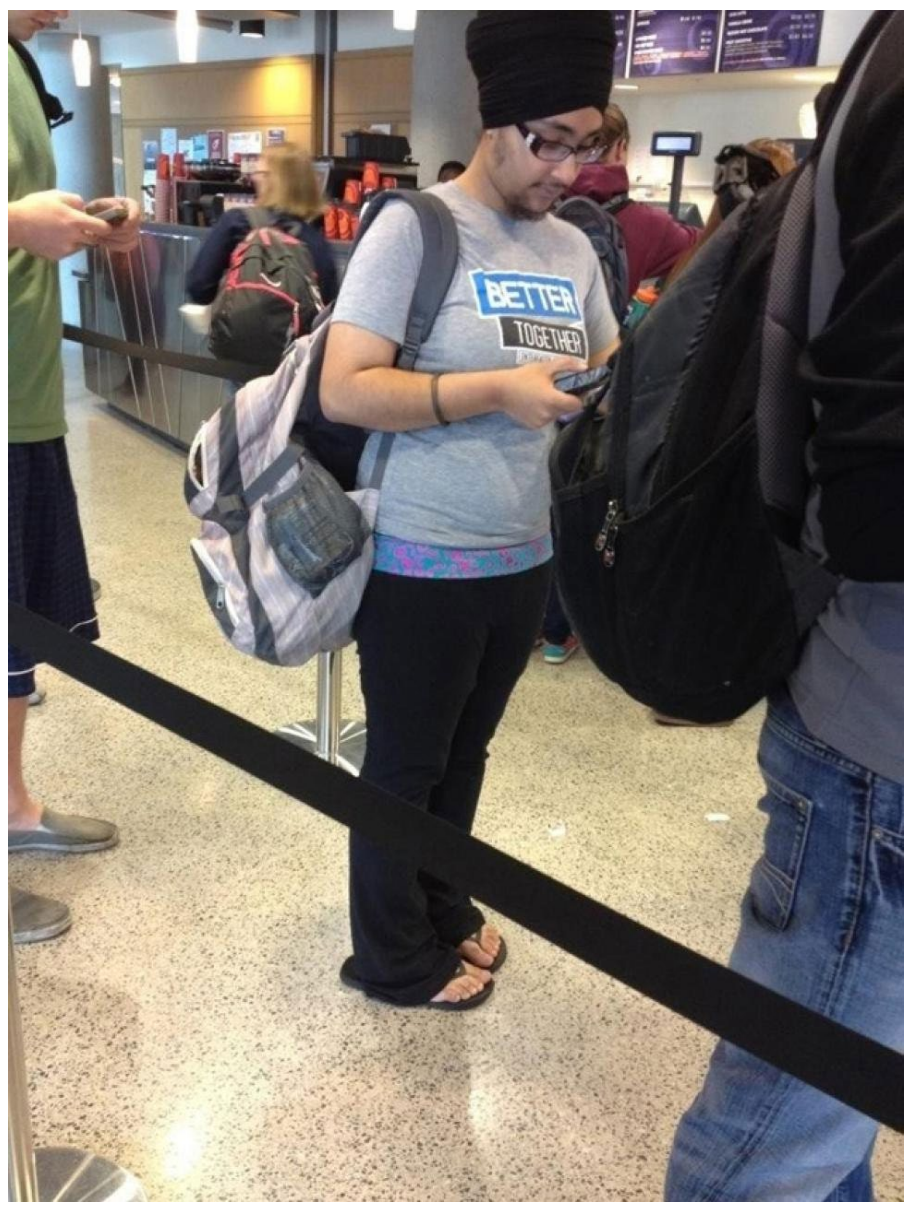

Figure 1. The photograph of Balpreet Kaur taken and posted to Reddit without her knowledge or consent. It has been republished here with permission of Ms. Kaur.

In response, multiple posters made crude and offensive jokes, referring often to her facial hair or what they assume is a middle eastern appearance. Specific comments include slurs against trans people and Muslims. (See footnote for examples. ${ }^{1}$ ) The language and sentiments used in these comments are not only uncivil and offensive, but openly hateful and dehumanizing, a response which seems to have been invited by that initial caption: "I'm not sure what to

1 One Reddit user uses the slur, "Pre-op tranny" (chasemedown, 2012). Another writes, "he/she probably didn't get 'randomly selected' to get patted down though. What did we learn here today?" (waywirk137, 2012) One attempt to insult both her facial hair and supposed ethnic and religious identity reads, "i know [sic] understand burkas" (Satchelbuck, 2012). 
conclude from this."

Shortly after the picture was posted, a friend of the photo's subject recognized her: the woman in the photo was Balpreet Kaur, then a neuroscience and psychology double major at the Ohio State University. After her friend told her about the picture, Kaur created a Reddit account and wrote a lengthy response to the original poster and subsequent commenters, patiently explaining her Sikh faith and how it shapes her outward appearance. Commenters praised her openness and vulnerability, and several days later the original poster commented with an apology to Kaur for taking her picture without her knowledge and mocking her appearance. Kaur's openness to dialogue and the positive responses she received were so unusual that the story was covered in mainstream media, from the Huffington Post (Bennett-Smith, 2012) to Shape Magazine (Nuñez, 2012).

In this article, I argue that a certain set of photographs of strangers, particularly those that invite such derogatory paratexts online, constitute a genre, which I am calling "strangershots." Strangershots are photographs taken of strangers without their knowledge or consent and then shared online, where they become powerful actants in digital networks. This genre of strangershots is identifiable not only by its form and content, but also by the social actions it accomplishes as a result of producing recognizably similar responses to recurring social situations. In other words, not all pictures of strangers online belong to the genre of strangershots; the genre is defined not only by its subjects, but also by its common use to shame and denigrate those subjects.

My goals in identifying and analyzing this genre are threefold. First, I apply new materialist theory, specifially as articulated through Bruno Latour's (2005) actor-network theory and explored in relation to rhetoric by Laurie Gries (2015), to demonstrate that this genre is 
produced not by individual rhetors, but by assemblages of humans and non-human technologies. Second, I provide a critical feminist reading of this genre that demonstrates how it reifies normalcy by leveraging biopower (Foucault, 1990) against non-normative bodies through explicit public shaming. Thus, this genre has emerged as a recurring social action in response to non-normative people daring to appear in public space despite their lack of adherence to social norms for appearance, comportment, or other visible attributes. The technological assemblage producing the genre, and the very notion of this genre as a regularized response to recurring social situations, has created new avenues for biopower to regulate individuals. Moreover, the emergence and spread of this genre not only provides rhetors with an opportunity to exercise biopower in service of regulating others' bodies; additionally, the very existence of this genre facilitates a productive version of power by motivating rhetors to exercise biopower in this way. Finally, I argue that this critical genre analysis can provide nuance to assemblage theories of composition pedagogy by valuing ethical analyses of assemblage genre's social actions alongside advocacy for teaching the kind of process and product at work in assemblages. In doing so, this analysis of strangershots helps us to meet the "digital imperative" (Clark, 2010) to make our classrooms reflect $21^{\text {st }}$-century technology-driven composition practices while meaningfully considering the social actions performed by the genres and texts we bring into those classrooms.

\section{Actor-Network Theory and Strangershots: New Assemblages Yield New Genres}

The internet is teeming with strangershots: pictures taken, uploaded, and mocked online, all without their subjects' consent. People circulate photographs of strangers widely through online networks; social media platforms such as Facebook, Instagram, Twitter, and Snapchat 
make trivial work of snapping a quick picture in public and sharing it. Twenty-first century media technology is hardly responsible for the emergence of this practice of taking pictures of strangers, however. For over a century, documentary and street photographers ${ }^{2}$ have specialized in training their photographic gaze on strangers. In their history of street photography, Westerbeck and Meyerowitz describe street photographers as those who mostly "have tried to to work without being noticed by their subjects. They have taken pictures of people who are going about their business unaware of the photographer's presence. They have made candid pictures of everyday life in the street" (1994, p. 34). In 2017, "candid pictures of everyday life" are increasingly ubiquitous thanks to concomitantly ubiquitous camera technologies and the networks of humans and nonhumans they are embedded in. It is no longer just documentary or street photographers who do this work of photographing unaware subjects; it is anyone with a camera-phone who has the impulse to snap a quick pic in public.

This ubiquity of potential photographers signals a fundamental shift in relations between people and photographic technologies. Street and documentary photography were initially the province of a limited set of people; the baseline technological and concomitant financial investment required to take photographs made them far rarer than in our contemporary milieu, defined as it is by the ubiquitous digital camera. Moreover, especially with street photography, the practice situates photographer, photograph, subject, and place in relations to each other that aren't also always true of strangershots. Kaur's example illustrates this starkly; she is indoors in a place of business, occupying a semi-public space where expectations of privacy can be quite different than expectations of privacy in the very public spaces of literal streets and other outdoor

\footnotetext{
2 While street and documentary photography share some potential connections to strangershots, they are typically treated as distinct movements. Enumerating those distinctions is beyond the scope of this paper, but an overview of them can be found in the introduction to Clive Scott's (2007) Street Photography: From Atget to Cartier-Bresson.
} 
places. While a reasonable expectation of privacy is an important legal concept in the U.S., particularly when it comes to the legality of taking and distributing photographs without their subjects' consent, I am using the term privacy here in a more general way to highlight people's varied expectations of surveillance on the street, in businesses, on college campuses, and across other spaces that range from clearly public to quasi-public to self-evidently private.

In addition to fewer people having had access to photographic technologies, the relative rarity of photographs of strangers in earlier decades might have had something to do with Susan Sontag's claim that "in photography's early decades, photographs were expected to be idealized images" (2001, p. 28). Interestingly, she goes on to write that "this is still [in the 1970s] the aim of most amateur photographers, for whom a beautiful photograph is a photograph of something beautiful, like a woman, a sunset" (2001, p. 28). She distinguishes here amateur from professional or artistic photographers, whom she describes as having "steadily drifted away from lyrical subjects, conscientiously exploring plain, tawdry, or even vapid material” (2001, p. 28). This move, from the "lyrical" to the "plain" subject, is a strong thread in narratives of photography's history, particularly in the U.S. The "plain" subject of later professional photography is understood to be elevated somehow through the act of being photographed. Becoming an artistic subject is an experience of metamorphosis, in which the final stage is one of newly recognizable beauty. Sontag grandly argues that "there is probably no subject that cannot be beautified; moreover, there is no way to suppress the tendency inherent in all photographs to accord value to their subjects" $(2001$, p. 28). This idea that the plain, the ugly, the everyday are as worthy of being captured on film as the classically beautiful and carefully staged has influenced multiple developments in the history of photography, including the broad movements of street and documentary photography. 
Where documentary and street photographers typically take as their purpose the documentation and artistic portrayal of everyday life, the capturing of scenes "characterized by constantly shifting configurations and micro events that often escape notice" (Durden, 2014, p. 137), the purposes of those who take pictures of strangers with their camera-phones are likely more diffuse. One purpose is widely shared, however: the shaming of people for their public embodiment and behavior. Such shaming functions as a form of epideictic rhetoric, "crystallizing and policing community norms, values, and identifications" (Nicotra, 2016, para. 3). The photographs are often accompanied by paratextual commentary mocking the strangers they feature, both directly and obliquely, laying bare their shaming function. I am adapting here Gérard Genette's concept of paratext, which he defines as those elements which surround a text "in order to present it, in the usual sense of the verb but also in the strongest sense: to make present, to ensure the text's presence in the world, its "reception" and consumption in the form (nowadays at least) of a book" (1997, p. 1). Similarly, the posts that accompany strangershot uploads and the comment threads that typically follow them serve a generic function, presenting the image as suitable for judgmental reception and visible consumption as an abject object of mockery. By deploying the notion of paratext, I aim to distinguish these generic elements from the catholic use of image captions across genres to label and describe (ostensibly) objectively. The practice of sharing pictures of strangers is popular enough to not only occur in isolated threads, such as the Reddit one I began with, but also to produce entire photographic corpora and web platforms dedicated to the practice. For example, on Tumblr, on his account "She Has Had It,"3 photographer Jarvis Derrell shares shots of "New York's most lovable hot

\footnotetext{
${ }^{3}$ I have chosen not to directly link to any of the strangershots sites or reproduce most of the specific strangershots I describe in this article. As Laurie Gries cautions in Still Life with Rhetoric, building on Jenny Edbauer's theorization of rhetorical ecologies (2005), the circulation of images enables their effects to exceed their original conditions of production (2015, p. 18-19). This article, in part, identifies these
} 
messes" (Hawgood, 2017, para. 1) taken without their subjects' consent. Derrell describes his project as “about telling people's stories...even if they're just made up in my head.” Another infamous example is the website "People of Walmart," to which people can submit pictures they have taken of people inside Walmart stores; the majority of these photographs bear the hallmarks of being secretly taken: their subjects are looking away from the camera and the images are often angled oddly or shot at a noticeable distance from their subjects. The paratextual commentary, as with the original comments responding to Kaur's picture posted on Reddit, typically jokes about or otherwise shames specific aspects of subjects' embodiment or behavior; comments are often unapologetically sexist, homomisic, fatmisic, transmisic, ${ }^{4}$ racist, classist, ageist, and anti-Islamic. These kinds of photographs, and the cruelty they invite, are even common enough to have spawned a spate of thinkpieces in recent years decrying their popularity (see e.g., Katz, 2017; Moss, 2017).

To make sense of this phenomenon, I draw on Latour's articulation of actor-network theory (ANT) as an approach to social scholarship (2005). For him, ANT scholarship generally meets three criteria: 1) it treats non-humans as agentic actors, 2) it explains the mutable social, rather than using a stable notion of the social to explain other phenomena, and 3) it works to build rather than deconstruct (2005, pp. 10-11). All three of these traits dovetail with an

images' potential to reify norms and harmfully police bodies. Therefore, my choice not to link directly to or reproduce them is an ethical one, derived from my knowledge that I cannot control whether--even in the new context of my article--my continued circulation of the images would perpetuate existing or enable new effects of the images with which I have fundamental ethical disagreements.

${ }^{4}$ In using the -misic suffix, I follow disability activists who have adopted it as an explicit rejection of more widespread language that relies on conceptualizing bigotries as "phobias." Freelance educator and disability activist $\mathrm{Eb}$ has argued extensively that -phobia suffixes referring to bigotry cause harm and should be replaced. In a series of tweets, they write, "Let's be real, though. The very fact that we call bigotries 'phobias' reinforces that false bigotry=MI [mental illness] connection" (2016b) and "If you want to help break that connection so we can put the onus of bigotry where it belongs, look into other words to describe bigotry" (2016a). As Eb (2017) discusses in a later Twitter thread, the origins of the -misic suffix as a replacement for -phobic are (as of this writing) not well documented, although some online uses seem to originate from 2007 or earlier. 
exploration of how genres develop and mutate, particularly in the context of new communication technologies. These new communication technologies are a key explanatory factor in the emergence of strangershots, a genre that depends on ubiquitous access to both cameras and online distribution technologies. By analyzing strangershots as products of both humans and non-humans in networked relationship, my work thus demonstrates in action Alex Reid's contention that "rather than beginning with the ontological premise that symbolic behavior is an intrinsic quality of being human, assemblage theory allows one to investigate symbolic behaviors as emerging from the external relations among humans and nonhumans" (2017, p. 29).

In pointing to the history of street and documentary photography's tradition of taking pictures of strangers in public, I want to suggest that the genre of strangershots neither represents an entirely new practice, not is it simply the result of a shift in the purpose of this pre-existing practice. Rather, it results from a shift in the fundamental material conditions of the practice. The ubiquity of smartphones means that the number of cameras and the number of opportunities for using them has multiplied exponentially in the 21 st century. Moreover, because of their incorporation into devices connected to countless digital networks, those cameras exist in a web of relations that is meaningfully distinct from the assemblages in which the handheld disposable camera or the affordable Brownie or the classic Leica were enrolled. In other words, I argue that strangershots are not just a product of an ill-intentioned individual, in possession of a camera and out to shame others. Rather, they are are the product of an individual with a camera with the capacity to upload images to the internet with access to sites that will host these image with the capacity to share and interact with these images via hyperlinks, like buttons, comment sections and so on. Strangershots aren't produced by individual humans. They're produced by human actors working with and through a network of other actors, both human and non-human--a 
network that results in strangershots that millions of people now have access to across any number of other website and social media platforms. Nicotra describes this approach to rhetorical production as an "assemblage framework," in which assemblages are "complex, dynamic entanglements of material and discursive factors that produce specific kinds of relations and effects" (2016, para. 9).

This insight about the network of actants underlying the strangershot draws on new materialist philosophy, and specifically Bruno Latour's theorization of technology as a nonhuman agentive actor. Latour gives a classic example of technology's agentive capacity to create new assemblages of actors with different outcomes in his 1994 essay "On Technical Mediation." Latour starts with the opposed claims: "Guns kill people." and "People kill people," and rejects a simplistic reading of both, instead arguing that a person-with-a-gun is a fundamentally different actor than the individual actors "person" and "gun." In other words, the gun is not simply one in a series of interchangeable technologies through which we might act on our pre-existing will to harm someone, kill out of revenge, defend our homes and so on. To take that point of view would be to accept that people have internal essences that are unaffected by the tools available to them - if I have decided in the heat of the moment to kill someone, my essential nature will see me follow through, whether what I have to hand is a gun or a knife or maybe just my fists. But clearly, the act of killing someone with fists is very different than that of killing someone with a gun. Latour makes this simple observation and extrapolates from it that "You are a different person with the gun in your hand" (1994, p. 32). His argument is that the technologies available to us shape us, our choices, and our actions.

The strangershots people gawk at online, including the photograph of Kaur with which I opened this piece, similarly emerge from the combination of human actor and non-human 
technology. The genre of strangershots only exists as a combination of human and non-human elements: photographers, mobile cameras, social media, wireless internet, subjects of photos. Their existence is further determined by cameras' ease of access, ease of use, speed of use, unobtrusiveness, available internet connections, battery life, and so on. The very fact that I can surreptitiously take an image of a stranger and post it to the website in a matter of minutes — if not seconds - is a result of my positioning as a new actor: not just a person, but a "person-with-asmartphone." That's a very different actor than, say, "person-with-a-disposable-camera-and-dialup-internet." To create and share a strangershot, that actor would have to carry a single-use and relatively noticeable technology into Walmart, snap a picture, get the film developed, scan it, and wait for it to upload over a phone line. It seems extremely unlikely that the thousands of current creators of strangershots uploading to sites such as Reddit and People of Walmart would go to such trouble. Thus, the strangershot as a genre is a product of a particular set of material circumstances that have produced the actor "person-with-a-smartphone."

To underscore this point, consider in somewhat closer detail how the smartphone raises and heightens the possibility of taking pictures of a strangers by reconfiguring financial barriers to photography. Not only are we more likely to have a camera handy in public at all times, we are also more likely to treat photographs as ephemeral texts, one or two or a dozen more of which cost us little in time, effort, or money. The basic question of the cost of a photograph makes this point rather starkly: for film photographs, one can calculate a rough estimate of the cost of each picture, accounting for the film and developing materials and time. Asking how much an individual digital photograph costs is nonsensical, however; the hardware that takes the picture may have a cost, as may the web access with which we upload it, but the picture itself is just one more of hundreds of bits of data we create and accumulate with our phones, none of 
which seem to have an individual price tag. No wonder, then, that the practice of taking pictures of everything--not just strangers, but also food and garbage and other assorted bits of everyday life--has become so popularized.

The production of a "strangershot" - a new material actor now extant and available to enact change in the world-relies on an assemblage of other actors, from the smartphone to the photographer to the servers that store the pictures. Latour reiterates this idea that the presence or absence of specific actors matters in Reassembling the Social; to determine an object's status as actor, there are two questions to ask: "Does it make a difference in the course of some other agent's action or not? Is there some trial that allows someone to detect this difference?" (2005, p. 71) Or, as Laurie Gries puts it, the actors that make up assemblages "have their own characteristics and dynamics, have potential to enact change, and are separable from an assemblage in which they participate" $(2015$, p. 61$)$. Investigating strangershots through the lens of new materialism thus belies the notion of the strangershot as the purely discursive result of an individual rhetor acting on an individual motive. New materialism instead brings into focus a network of actors, each a change agent, which collectively lead to the repeated composition of strangershots and their continuous circulation in the world.

To reiterate, it is not that no one had taken pictures of strangers before the smartphone or the internet, as the longstanding fields of street and documentary photography establish. Rather, the technology of the smartphone is a new actor, which in conjunction with other actors-some new, some old - has produced yet more actors, which in turn opens new possibilities for action. Thanks to these assemblages of actors, photographs of strangers can become ubiquitous, widely distributed, and — crucially—can serve new purposes, thus developing into another genre altogether. In her landmark argument for understanding genre as social action, Miller argues that 
theories of genre must account for just this kind of change, for "new members evolving, old ones decaying" (1984, p. 153). A materialist perspective informed by actor-network theory offers such an understanding of change, providing an explanatory theory for how new forms of discourse, such as the strangershot, arise in digital spaces.

One important point, though, is that even though the genre may be new, the strangershot serves a very well-established function: that of surveillance and discipline. Surveilling and disciplinary practices (re)produce biopower as a relational force shaped by conceptualizations of normality and deviance. The genre of strangershots functions as such a practice, serving as a recurring response to a complex exigence that not only reifies ideas about what bodies may move through public space but also (re)produces those ideas as photographers, audience, and subjects interact with these texts. In the following sections, I first analyze how existing models of “cybergenres" fail to account for strangershots' particularities, then turn to an exploration of how strangershots' functions of surveillance and discipline reveal biopower as the genre's underlying motive.

\section{The Limitations of Defining Genre Formally}

The influence of technological developments on genre and genre development has been the subject of scholarly investigation in multiple fields for at least two decades. Outside of rhetorical studies, genre is often defined in formal terms (see e.g., Roussinov, Crowston, Nilan, Kwasnik, Cai, \& Liu, 2001; Shepherd \& Watters, 1998), including in digital genre studies. In a frequently cited 1998 proceedings paper, computer scientists Michael Shepherd and Carolyn Watters (1998) coined the term "cybergenre" to refer to texts that appeared as a result of "the combination of the computer and the Internet" (para. 3). Their understanding of genre is rooted 
in formalism, defining genres initially by virtue of their "having similar content and form" (para. 3, original emphasis). To these two features, Shepherd and Watters add "functionality" as a key feature of cybergenres, with functionality referring to medium-specific attributes that enable the evolution of legacy genres and the emergence of altogether novel ones (para. 6). While their attention to functionality and to genres' mutability more generally make theirs a relatively flexible formal model of genre, the model maintains an emphasis on shared features as the defining characteristics of any given genre. As such, it reductively treats genres as collections of set characteristics, rather than rhetorically responsive and mutable assemblages.

Such limitations of formal models of genre have been well articulated, particularly by Carolyn Miller, and in subsequent scholarship drawing on her "truly rhetorical" approach to genre that approaches that treat genre as a static response to fully articulatable rhetorical situations (Dryer, 2015). A key limitation that rhetorical treatments of genre overcome is a fundamental misconception of genre as static; such a misconception can leave attempts to classify new genres and iterations of genres forever scrambling to catch up to their transformations. This need to understand genres as contextually responsive and mutable is highlighted as new technologies reshape those contexts increasingly quickly. Genres emerge, Miller argues, as already complex rhetorical situations reconfigure themselves in response to a constellation of developments, such as "specific new technologies and more general trends in socioeconomic conditions" (2017, p. 14).

Moreover, formal classification of genre might actually be inadequate for distinguishing among genres with similar content, form, and functionality. Strangershots provide a case in point; images of strangers abound online, but they do not all seem of the same sort. For example, compare the photograph of Kaur with photographer Stefan Draschan's series "People Matching 
Artworks." In it, Draschan captures photos at museums of visitors whose clothing, hairstyle, or other attribute somehow "match" the artwork they are contemplating. The photographs are all taken from behind; their subjects are unaware that they are being photographed. Draschan characterizes these images as “'Streetphotography” pure," with which he creates visual connections between the disparate time periods of the artworks and the contemporary viewers (“Stefan Draschan" n.d.). Like strangershots, his work relies on technological assemblages of people, innocuous and ubiquitous cameras, digital sharing technologies, and other actors. Much like the Redditor's surreptitious photographing of Kaur, Draschan takes quick digital shots of the same unposed, unaware subjects in order to find the one that best achieves his purpose. And this purpose, unlike with the photograph of Kaur, is not to mock the subjects, but to make art of their likenesses. Formally, though, Draschan's photographs could easily be lumped into a shared category with the photograph of Kaur. What distinguishes them is thus their effects, offering a different dimension along which to classify genres. Of course, in rhetoric, this decoupling of genre from formal definitions is hardly new, nor is the turn to purpose as a primary classificatory attribute; both moves illustrate Carolyn Miller's argument that focusing on "the action it is used to accomplish" provides "a rhetorically sound definition of genre" (1984, p. 151) that accurately reflects how rhetors and texts interact. Turning to this approach to genre, I next take up the question of what social action strangershots as a genre are aiming to accomplish.

\section{The Genre of Strangershots: Typified Rhetorical Action in Service of Biopower}

In arguing that genre is best understood as rhetorical action, Miller posits that genre must "involve situation and motive, because human action, whether symbolic or otherwise, is interpretable only against a context of situation and through the attributing of motives" (1984, p. 
152). Defining a new genre thus requires identifying the rhetorical action it accomplishes within particular situations and in response to particular motives. The rhetorical situation to which strangershots respond appears to be a fairly common one: a rhetor with a smartphone camera finds themselves in a public place with at least one other person, whom — for some reason-they find worthy of photographing. That "for some reason" stands in for Miller's second concern: motive.

While I cannot claim to know any particular photographer's motivation for taking and sharing strangershots, as a genre, the assemblages creating strangershots have a shared effect: mockery of their subjects. This mockery is typically laid bare in the captions and comments attached to these images, full of jokes about and performed disgust at others' appearances and behaviors. For example, after Reddit user european_douchebag posted Kaur's picture, many of the initial comments on it referred mockingly to Kaur's facial hair and turban, both directly and indirectly. (See footnote for examples. ${ }^{5}$ ) These comments are just a small sampling, and they are similar to those that crop up around strangershots not only on Reddit but across digital platforms. Such mockery makes explicit whatever it is about the subject that is deemed too abnormal for public appearance, and often--as in the case of Redditor european_douchebag--the original strangershot poster sets the stage for this mockery with a comment of their own. However, to some extent, a genre's emergence obviates the question of the original rhetor's individual motive, as "....at the level of the genre, motive becomes a conventionalized social purpose, or

${ }^{5}$ Direct references include "bitch got a beard" (Silently_judging, 2012) and "That girl is HOT! Although I have heard that her mustache gives you friction burns..." (poonJavi39, 2012). A particularly offensive comment reads, "It has tits and a beard" (username deleted, 2012). Here, the use of "it" as a pronoun to refer to Kaur suggests that her gender performance is non-normative, thus stripping her of the human status that the gendered pronouns "she" and "he" would convey. Similarly, other comments use nongendered pronouns to imply that Kaur is not appropriately feminine or masculine: the comments"WHAT is that?" (Unalive, 2012) and "Wait, that's legitimately a female? $\odot \_\odot$ I thought it was just a really gender confused guy...." (1336plus1, 2012) both use "that" to suggest that Kaur's appearance is disorientingly unusual, enough so to dehumanize her. 
exigence, within the recurrent situation...We learn to adopt social motives as ways of satisfying private intentions through rhetorical action" (Miller, 1984, p. 162). Moreover, the previous new materialist analysis of strangershots as an actor produced by an assemblage of other actors calls us to question articulations of motive that rely on individual rhetors' intentionality. Instead, new materialism's recognition of the multiplicity of actors and their imbrication with each other complicates the role of motivation in accounting for rhetoric; this complication follows directly from materialism's opening up of questions about what agency is, with whom it resides, and how it comes to be exercised. As Megan McIntyre compellingly argues, we can better understand rhetoric's effects and effectiveness in the world by "mak[ing] room in our theories of rhetorical and material agency for the others - human and nonhuman - who have always worked against, with, and alongside human rhetors" $(2015$, p. 27). For strangershots, the genre's conventionalized social purpose is made apparent by the paratext accompanying it, which is usually shot through with mockery and shaming. No matter the details or nuances of an individual strangershot creator's motivation, the outcome of the combined agentic forces of the assemblage producing the strangershot is mockery of others.

This mockery, with its focus on others' appearances and behaviors, is a recurring social action that follows in the wake of the strangershot genre. Following Miller's assertion that genres are regularized responses to recurring situations intended to accomplish social actions, identifying the genre of the strangershot raises the question of what recurring situation it is responding to and what social actions it is thereby accomplishing. The recurring situation is not marked by an institutionalized or formal exigence (as is the case with genres such as tax forms and college applications), but rather is initiated by the moment of seeing a person who appears non-normative in some way. This non-normativity is enough, it would seem, to warrant 
comment, and the genre of strangershots has emerged as a way to both comment and invite further comment. And, as noted above, these comments are not neutral. They are frequently critical and mocking, suggesting that the social action the genre accomplishes is one of shaming. Shaming serves a policing function; it tells us what's acceptable and what isn't, which bodies are supposed to appear in public and which aren't, which behaviors are socially permissible and which aren't.

The strangershot thus becomes a tool by which anyone in public can both surveil and police others. Surveilling and policing are critical processes in the application of what Michel Foucault calls bio-power, which is the mechanism by which we subject people to processes that "qualify, measure, appraise, and hierarchize" (1990, p. 266). These are processes that have the effect of "distributing the living in the domain of value and utility" (1990, p. 266). In other words, bio-power normalizes persons and their bodies according to institutionalized standards based on an ethic of use-value and value production. Moreover, bio-power depends on people internalizing and responding to those normalized standards. Foucault argues that in modernity, this is a process of self-disciplining and self-surveillance--we know we're supposed to behave and look in certain ways, so we do--not to avoid, say, legal punishment--but to be "proper" and “normal." What strangershots demonstrate is that this self-surveillance underpinning Foucault's notion of discipline and biopower is joined by a new form of surveillance--private biocitizens surveilling and disciplining each other in the extended discursive networks enabled by the web.

Of course, normalization relies on assessment of adherence to norms. Biopower thus becomes an explanatory concept for the ways in which modern individuals and populations are assessed and, through that assessment, disciplined and controlled. As examples of individual disciplining, Foucault presents "reflections on tactics, apprenticeship, education, and the nature 
of societies," and of the bio-power underlying population control, he gives us "demography, the evaluation of the relationship between resources and inhabitants, the constructing of tables analyzing wealth and its circulation" (1984, p. 262). These discourses generate normative ideals which individuals are disciplined to aspire to in the service of "value and utility." How individuals do act becomes but a comparison to how they should act. And it is in this comparison that the inevitable dark underbelly of normalization arises: the manufacturing of abnormality.

So biopower establishes norms, and disciplinary tactics maintain them and provide cover for the shaming of those who don't. We see these processes at work in strangershots. Take, for example, the vast swathes of commentary surrounding strangershots that focus on the image subject's weight. Like Balpreet Kaur, subjects of some such fatmisic strangershots have learned of their image being mocked online. Amy Salloway (2014), a fat woman, writes about "the humiliation, the shaming" she experienced when a photograph of her sitting on a chair on a treadmill in street clothes was posted to the website Youredoingitwrong.com. Similarly, after reading fatmisic comments on a picture of her dressed as the video game character Lara Croft went viral, Caitlin Seida (2013) wrote that "We all know the awful humiliation of a person laughing at you. But that feeling increases tenfold when it seems like everyone is laughing at you." This shared sense of humiliation results from the strangershots' invitation of mockery, which in this case relies on a hierarchization of fat as bad and thin as good. This moral assessment of body size is one example of biopower's function; by drafting medical and health discourses to create a conceptualization of "normal" bodies, biopower's workings enable bodies in excess of the norm to be labeled deviant: a result of bad decisions, bad behavior, badness.

Once biopower has yoked fat to negative moral judgments, commenters on strangershots are free to deploy a variety of disciplinary tactics to maintain this relationship, ranging from mockery to 
"concern trolling" (giving unsolicited advice and criticism supposedly out of concern for the message's recipient). Furthermore, biopower allows similar moral judgments and concomitant disciplining to be imposed on bodies with other visible markers, such as of poverty (Adair, 2002) and race (McWhorter, 2004). Such stigmatization is hardly new, of course; but the assemblage producing strangershots does provide a new mechanism for its production and application.

Emerging from an assemblage of other actors, strangershots are actants that enable the circulation of disciplinary discourses that teach us which bodies are acceptable and which are transgressive. These non-normative bodies, strangershots would suggest, are so transgressive as to call forth public mockery as a rhetorical reminder to all subjects that we must constantly surveil and discipline both our bodies and others' bodies. Otherwise, we might next find ourselves circulating across the pages of Reddit and "People of Walmart" and even the more insular networks we travel on Facebook or Instagram or other social media. Intervening in these networks--at both their discursive and their material levels--to highlight and critique this surveillance and its (re)production of systems of oppression is crucial to efforts at advancing social justice in the digital spaces where so many of us now live out so much of our lives.

\section{Assembling Strangershots and/in the Teaching of Composition}

Given strangershots' ubiquity, this genre offers a pedagogical opportunity to meet the "digital imperative" that J. Elizabeth Clark described as "a challenge to articulate how technology is radically transforming our understanding of authors and authority and to create powerful new practices to converge with this new digital world" (2010, p. 27). Identification of this challenge is not unique to Clark; she roots her description of it in Kathleen Blake Yancey's, Richard Lanham's, and James Gee's work, among others. However, Clark's coining of the term 
"digital imperative" is in recognition of the fact that while technology's relevance to composition may have been obvious for some time to Computers and Composition readers, it has not always been so obvious to the broader field of composition, which she critiqued for its continued emphasis on "traditional essayistic literacy" (2010, p. 28). Eight years later, Clark's call to action for composition pedagogy to center digital media and literacy seems perhaps far more selfevident. Increased access to technology in and out of classrooms, availability of open-source software, and spread of bring-your-own-device (BYOD) policies all contribute to and illustrate the uptake of digital approaches in higher education pedagogy more generally, as well as in composition specifically.

As an online genre that students might regularly encounter in their non-academic digital lives, strangershots could allow instructors to develop students' digital literacy and composition skills by connecting key concepts from digital rhetoric (e.g., genre, technological affordances, circulation) to familiar types of composition. These key concepts can also be taught under the umbrella of assemblage theory, as is persuasively argued by McElroy and Maynard in their description of a first-year composition curriculum framed around assemblage as a process for and product of composition (2017). Strangershots fit nicely into this pedagogical approach, given the argument I made above about strangershots being produced by networked relations of humans and non-humans.

Conceivably, strangershots might be especially useful for teaching students about the role of non-human technologies in assemblages, as the contrast between street photography in earlier eras and contemporary strangershots in the era of the smartphone so clearly shows how technological affordances shape and change even existing types of compositions, yielding new kinds of assemblages born of other assemblages. Using this contrast, for example, one could 
design an activity or assignment that deploys strangershots to prompt student reflection on two key questions raised in Alex Reid's theoretical exploration of composition as an act of assemblage: "First, if we conceive of composing as a process involving the participation of human and nonhuman objects rather than one located strictly within human beings (or human beings and some amorphous "culture"), what might we learn? And second, and more important, how might such a supposition shift and expand our conception of what is possible?" (2017, p. 28). In some ways, this article is in fact a response to these very questions.

However, it is crucial to note that I am not uncritically advocating the incorporation of strangershots into composition pedagogy. Rather, I think there is an obvious need to consider whether the genre's social effect of reproducing biopower should give us pause before using it as a teaching tool. Of course, all genres have social effects; that is, according to Miller's (1984) analysis, one of their most defining characteristics. As such, genre-based pedagogies should support student uptake of rhetorically informed genre analysis and production that enables students to move beyond rote repetition of formal features and prescribed content to attend to genres' social actions. Both Michaud (2017) and McElroy and Maynard (2017) propose that such approaches to genre can make valuable contributions to assemblage pedagogies. Teaching genre rhetorically allows students to see how genres themselves are assemblages (Reid, 2017) and specifically assemblages produced in response to "a set of flexible 'expectations' rooted in cultural traditions" (McElroy \& Maynard, 2017, p. 109). But what do we do as instructors with genres whose social actions include upholding cultural traditions that are harmful, such as mocking others for their non-normative embodiments?

This question is fraught enough that I have not yet used strangershots pedagogically, at least not deliberately. The genre has come up tangentially in my classroom during discussions of 
social media, for example. But I am hesitant to center it, and I am particularly loath to show examples of it, as further circulating strangershots could perpetuate their production of biopower (although, as Gries (2015) points out, images shift in their effects as their context of use and circulation shift). That said, students are aware of this genre; they may even encounter it regularly as they navigate the web and social media. It is part of "the world beyond the classroom" which Clark claims the digital imperative would have us explore with students. In that case, we would be remiss not to address strangershots—or any other similarly ubiquitous genre-simply because of their production of biopower or other problematic social effects. Using strangershots to teach assemblage theory and composing practices would require us, however, to dwell on their problematic aspects with students. This genre is clearly not a neutral example of assemblage. Rather, like all rhetoric, it is composed of and by politically charged assemblages. As an obvious example of this political charge, strangershots offer an opportunity to avoid treating assemblages as amoral, instead highlighting how they can carry moral valences in their production and effects. In one of the most cited articles in this area, Johnson-Eilola and Selber's (2007) "Plagiarism, Originality, Assemblage," the authors argue persuasively that assemblage theory prompts us to imagine a wider array of responses to rhetorical situations than purely text-based and author-centric theories do. They write of these rhetorical situations that they are "at base, problem-solving situations in one way or another" (2007, p. 400), which could be read to imply that assemblages are useful and good because they enable creative problem-solving. The notions of creativity and problem-solving carry positive connotations in contemporary U.S. culture and in the student-centered pedagogies that have been embraced by many compositionists.

However, creativity and problem-solving, like other rhetorical tools, can be put to many 
purposes. Not all things are problems, and not all problems should be solved. Strangershots undermine an unreflectively positive view of assemblage as problem-solving technique by compelling us to ask what problem is being solved by the viral mockery of strangers online. The analysis I've presented here answers that question: it is the problem of people with nonnormative embodiments daring to exist in public, to be visible within range of a stranger with a cameraphone. My ethical commitments to intersectional feminism (Crenshaw, 1991) lead me to critique this answer, however, as visibility for all is important and should not predictably lead to harassment and violence. Biopower's use of assemblages to define non-normative embodiment as a problem and police transgressors is itself a problem. Assemblage-based problem-solving can harm. It is not always desirable.

\section{Conclusion}

The strangershot is a new genre that has emerged from the possibilities generated by a complex assemblage of digital photography and communication technologies. While it relies on practices already in use in other forms of photography, such as photographing strangers without that knowledge or consent, the strangershot's regularized use to surveil and shame others delimits it as a distinct genre in service to the social action of extending biopower's reach.

Importantly, the genre of strangershots is not simply a tool for restricting bodies through epideictic shaming. Rather, it is also a construct that produces, through the recurring reproduction of strangershots, a "cultural rationality" (Miller, 1984, p. 165) that calls forth such shaming from rhetors. An understanding of genre as social action thus enables us to see how genres enable a Foucauldian version of productive power. In the case of strangershots, the genre produces both the concept of bodies in need of shaming and the rhetorical response of shaming 
through picture taking, both of which are concepts in service to biopower.

Miller identified this productive power of genre when she suggested that genres function not only as a response to recurring rhetorical situations, but also as categorical constructs that enable rhetors to recognize what might be a recurring rhetorical situation to begin with. Through the lens of new materialism's concern for the nonhuman and shifting of agency away from the purely intentional and anthropocentric, genre can be understood as an emergent property of human and non-human assemblages. These assemblages' imbrication with each other produces power, which is concentrated and focused on particular subjects through the repetitive use of recognizable rhetorical responses to recurring rhetorical situations.

Latour's call to "trace the actors" echoes Miller's exhortation to identify the action in genre. if we just look at final products--whether that's some essentialized version of the "social" or some essentialized list of genre features--then we miss the becoming work that these actors are doing within their assemblages. Dismissing strangershots' use to mock others as just bad behavior of bad people overlooks a crucial fact about them: that they are the products of assemblages that, while new, are working towards the familiar end of endlessly policing the boundaries of normative and non-normative. Analyzing the function of both assemblages and biopower is necessary to understand how this genre has emerged and why it pushes rhetors to take harmful social actions in response to the utterly commonplace recurring situation of someone showing up in public who happens not to fit their idea of "normal." In turn, if I respond to the digital imperative by teaching assemblage theory, strangershots can be a useful way to do that. To deploy this genre ethically, however, my critique of strangershots is no less important a part of my pedagogy than my exploration of how they are assembled. Strangershots thus illustrate how assemblage composition brings peril along with its promise, and we should devise 
pedagogical approaches that demonstrate both.

\section{References}

1336plus1. (2012, September 21). Re: I'm not sure what to conclude from this. [Reddit comment]. Retrieved from https://www.reddit.com/r/funny/comments/109cnf/im_not_sure_what_to_conclude_from this/?sort=old. Accessed 11 November 2017.

Adair, Vivyan C. (2002). Branded with infamy: Inscriptions of poverty and class in the United States. Signs, 27(2), 451-471.

Bennett-Smith, Meredith. (2012, September 27). Balpreet Kaur, Sikh woman, receives remarkable apology from redditor who posted her photo.

https://www.huffingtonpost.com/2012/09/27/balpreet-kaur-receives-recieves-remarkableapology-from-redditor_n_1919336.html. Accessed 19 December 2017.

Chasemedown. (2012, September 21). Re: I'm not sure what to conclude from this. [Reddit comment]. Retrieved from https://www.reddit.com/r/funny/comments/109cnf/im_not_sure_what_to_conclude_from _this/?sort=old. Accessed 11 November 2017.

Clark, J. Elizabeth. (2010). The digital imperative: Making the case for a $21^{\text {st }}$-century pedagogy. Computers and Composition, 27(1), 27-35.

Crenshaw, Kimberlé W. (1991). Mapping the margins: Intersectionality, identity politics, and violence against women of color. Stanford Law Review, 43(6), 1241-1299.

Draschan, Stefan. (n.d.). People matching artworks. https://peoplematchingartworks.tumblr.com/?og=1. Accessed 19 December 2017. 
Dryer, Dylan B. (2015). An interview with Carolyn R. Miller. Composition Forum, 31. http://compositionforum.com/issue/31/carolyn-miller-interview.php. Accessed 11 November 2017.

Durden, Mark. (2014). Photography today. London New York: Phaidon.

Eb [@ebthen]. (2017, November 5).\#EbMetaThread On “-Phobia” to Describe Oppression \#DisabilityandLanguage [Tweet]. Retrieved from https://twitter.com/EbThen/status/927356992578088960. Accessed 13 June 2018.

Eb [@ebthen]. (2016a, June 12). If you want to help break that connection so we can put the onus of bigotry where it belongs, look into other words to describe bigotry [Tweet]. Retrieved from https://twitter.com/EbThen/status/742051928201433088. Accessed 11 November 2017.

Eb [@ebthen]. (2016b, June 12). Let's be real, though. The very fact that we call bigotries 'phobias' reinforces that false bigotry=MI [mental illness] connection [Tweet]. Retrieved from https://twitter.com/EbThen/status/742051170378743808. Accessed 11 November 2017.

Edbauer, Jenny. (2005). Unframing models of public distribution: From rhetorical situation to rhetorical ecologies. Rhetoric Society Quarterly, 35(4), 5-24. https://doi.org/10.1080/02773940509391320

European_douchbag. (2012, September 21). Re: I'm not sure what to conclude from this. [Reddit comment]. Retrieved from https://www.reddit.com/r/funny/comments/109cnf/im_not_sure_what_to_conclude_from _this/?sort=top. Accessed 11 November 2017. 
Foucault, Michel. (1990). The history of sexuality (Vintage Books Edition, Vol. Volume 1: An Introduction). New York: Random House.

Genette, Gérard. (1997). Paratexts: Thresholds of interpretation. (J. E. Lewin, Trans.). Cambridge ; New York, NY, USA: Cambridge University Press.

Gries, Laurie E. (2015). Still life with rhetoric: A new materialist approach for visual rhetorics. Logan: Utah State University Press.

Hawgood, Alex. (n.d.). New York posts. https://www.wmagazine.com/story/jarvis-derrell-shehas-had-it. Accessed 20 November 2017.

Johnson-Eilola, Johndan., \& Selber, Stuart A. (2007). Plagiarism, originality, assemblage. Computers and Composition, 24(4), 375-403. https://doi.org/10.1016/j.compcom.2007.08.003

Katz, Evan Ross. (2015, March 27). Is it ethical to share photos of strangers on the internet? https://www.menshealth.com/guy-wisdom/snapping-photos-of-strangers-and-mockingthem. Accessed 20 November 2017.

Latour, Bruno. (1994). On technical mediation - Philosophy, sociology, genealogy. Common Knowledge, 3(2), 29-64.

Latour, Bruno. (2005). Reassembling the social an introduction to actor-network-theory. Oxford; New York: Oxford University Press. Retrieved from http://site.ebrary.com/id/10233636 McIntyre, Megan. (2015). Agency matters. Peitho, 25.

Mcwhorter, Ladelle. (2004). Sex, race, and biopower: A Foucauldian genealogy. Hypatia, 19(3), 38-62. https://doi.org/10.1111/j.1527-2001.2004.tb01301.x 
McElroy, Stephen J., \& Maynard, Travis. (2017). Copy, combine, transform: Assemblage in first-year composition. In K. B. Yancey \& S. J. McElroy (Eds.), Assembling Composition (p. 101-119). Urbana, IL: National Council of Teachers of English.

Michaud, Michael J. (2017). Assemblage composing, reconsidered. In K. B. Yancey \& S. J. McElroy (Eds.), Assembling Composition (p. 81-100). Urbana, IL: National Council of Teachers of English.

Miller, Carolyn R. (1984). Genre as social action. Quarterly Journal of Speech, 70, 151-167.

Miller, Carolyn R. (2017). Where do genres come from? In C. R. Miller \& A. R. Kelly (Eds.), Emerging Genres in New Media Environments (pp. 1-34). Cham, Switzerland: Palgrave Macmillan.

Moss, Emily Heist. (2014, June 9). Why we should stop posting photos of strangers online. http://www.rolereboot.org/culture-and-politics/details/2014-06-stop-posting-photosstrangers-online/. Accessed 20 November 2017.

Nicotra, Jodie. (2016). Disgust, distributed: Virtual public shaming as epideictic assemblage. Enculturation. Retrieved from http://enculturation.net/disgust-distributed

Nuñez, Alanna. (n.d.). Woman has an awesome response to cyberbullying. https://www.shape.com/blogs/shape-your-life/woman-has-awesome-responsecyberbullying. Accessed 19 December 2017.

poonJavi39. (2012, September 21). Re: I'm not sure what to conclude from this. [Reddit comment]. https://www.reddit.com/r/funny/comments/109cnf/im_not_sure_what_to_conclude_from _this/?sort=old. Accessed 11 November 2017. 
Reid, Alex. (2017). Big data assemblies: Composing's nonhuman ecology. In K. B. Yancey \& S. J. McElroy (Eds.), Assembling Composition (p. 26-41). Urbana, IL: National Council of Teachers of English.

Roussinov, Dmitri; Crowston, Kevin; Nilan, Mike; Kwasnik, Barbara; \& Cai, Jin. (2001). Genre based navigation on the web. In System Sciences, 2001. Proceedings of the 34th Annual Hawaii International Conference on (pp. 1-10). IEEE.

Salloway, Amy. (2014, August 20). I am the woman you laughed at on the Internet. https://www.dailydot.com/via/i-am-woman-you-laughed-at-internet/. Accessed 19 December 2017.

Satchelbuck. (2012, September 21). Re: I'm not sure what to conclude from this. [Reddit comment]. https://www.reddit.com/r/funny/comments/109cnf/im_not_sure_what_to_conclude_from _this/?sort=old. Accessed 11 November 2017.

Scott, Clive. (2007). Street photography: From Atget to Cartier-Bresson. London: Tauris-Verl.

Seida, Caitlin. (2013, October 2). My embarrassing picture went viral. https://www.salon.com/2013/10/02/my_embarrassing_picture_went_viral/. Accessed 19 December 2017.

Shepherd, Michael, \& Watters, Carolyn. (1998). The evolution of cybergenres (Vol. 2, pp. $97-$ 109). IEEE Comput. Soc. https://doi.org/10.1109/HICSS.1998.651688

Silently_judging. (2012, September 21). Re: I'm not sure what to conclude from this. [Reddit comment]. https://www.reddit.com/r/funny/comments/109cnf/im_not_sure_what_to_conclude_from _this/?sort=old. Accessed 11 November 2017. 
Sontag, Susan. (2001). On photography. New York: Picador USA.

Stefan Draschan - People matching artworks. (n.d.). https://www.lensculture.com/stefandraschan?modal=project-328813. Accessed 6 November 2017.

Username deleted. (2012, September 21). Re: I'm not sure what to conclude from this. [Reddit comment]. https://www.reddit.com/r/funny/comments/109cnf/im_not_sure_what_to_conclude_from this/?sort=old. Accessed 11 November 2017.

waywirk137. (2012, September 21). Re: I'm not sure what to conclude from this. [Reddit comment]. https://www.reddit.com/r/funny/comments/109cnf/im_not_sure_what_to_conclude_from _this/?sort=old. Accessed 11 November 2017.

Westerbeck, Colin, \& Meyerowitz, Joel. (1994). Bystander: a history of street photography (1st ed). Boston: Little, Brown. 